\title{
Remote-predictive geologic mapping of the Reykjanes Ridge: Implications for volcanic and structural evolution of a slow-spreading mid-ocean ridge
}

\author{
SOFIA PANASIUK ${ }^{1}$ MELISSA O. ANDERSON ${ }^{1}$, ÁRMANN \\ HÖSKULDSSON $^{2}$, FERNANDO MARTINEZ ${ }^{3}$, DOMINIK \\ PAŁGAN $^{4}$ \\ ${ }^{1}$ Dept. of Earth Sciences, University of Toronto, Toronto, \\ Canada \\ ${ }^{2}$ School of Engineering and Natural Sciences, University of \\ Iceland, Reykjavik, Iceland \\ ${ }^{3}$ SOEST, University of Hawai'i at Manoa, Hawaii, USA \\ ${ }^{4}$ Institute of Oceanography, University of Gdańsk, Poland
}

The Reykjanes Ridge presents an opportunity to study structural and volcanic features that are unique to slowspreading divergent plate boundaries overlying a mantle anomaly. The regional mantle anomaly may have been emplaced prior to the rifting that separated Greenland, Eurasia and North America [1]. The northern segment of the Mid Atlantic Ridge is a host to features including axial volcanic ridges (AVRs), rotated faults and N-S size gradients in the spacing and lengths of transform faults [1]. A number of these structures are atypical of a slow-spreading $(\sim 20$ $\mathrm{mm} /$ year) ridge [1]. To investigate the relationship among structures, volcanism, and regional geodynamics, we developed a novel remote-predictive geological mapping method based on interpretations from newly-acquired and compiled bathymetric data. Notably, bathymetric data coverage is extensive in this region, allowing us to develop a map legend that extends off-axis for the first time. The mapped area includes $900 \mathrm{~km}$ along axis, and up to $200 \mathrm{~km}$ off-axis, mapped at a scale of 1:1000000. Mapped structural features include major and minor faults, volcanic ridges/fissures, and other lineaments. Mapped volcanic features include AVRs, seamounts and hummocky to lobate lava flows [1]. Analyses of the relative positions and orientations of the structures, together with the distribution and morphology of volcanic features, leads to a comrehensive interpretation of the tectonic and mantle regime in the context of a constuctive plate boundary. This work is providing new insights into the fundamental controls on the development of diffuse low-temperature vs. focused high-temperature hydrothermal venting.

[1] Martinez et al., 2019. Reykjanes Ridge evolution: Effects of plate kinematics, small-scale upper mantle convection and a regional mantle gradient. Earth-Science Reviews (in press). 